\title{
Ginkgolide B enhances the differentiation of preosteoblastic MC3T3-E1 cells through VEGF: Involvement of the p38 MAPK signaling pathway
}

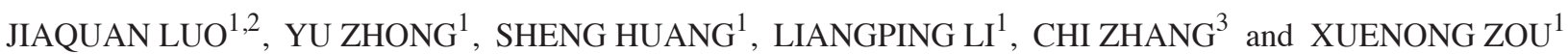 \\ ${ }^{1}$ Guangdong Provincial Key Laboratory of Orthopedics and Traumatology, \\ The First Affiliated Hospital of Sun Yat-Sen University, Guangzhou, Guangdong 510080; \\ ${ }^{2}$ Department of Orthopaedics, The First Affiliated Hospital of Nanchang University, Nanchang, Jiangxi 330006; \\ ${ }^{3}$ Department of Pharmacology, Peking University International Hospital, Beijing 102206, P.R. China
}

Received September 21, 2015; Accepted September 29, 2016

DOI: $10.3892 / \mathrm{mmr} .2016 .5829$

\begin{abstract}
Ginkgolide B (GB) is one of the ginkgolides isolated from the leaves of the Ginkgo biloba tree. Our previous study indicated that GB promotes the proliferation, migration and adhesion of endothelial progenitor cells, and the induction of angiogenesis through vascular endothelial factor (VEGF). In the present study, the effects of GB on the differentiation of MC3T3-E1 cells and the signaling pathway involved were investigated in vitro. The MC3T3-E1 cell viability activities were assessed using an MTS assay. Measurements of alkaline phosphatase activity and Alizarin Red staining were used to identify osteoblastic differentiation of the MC3T3-E1 cells. The mRNA and secretion levels of VEGF were detected using reverse transcription-quantitative polymerase chain reaction (RT-qPCR) analysis and enzyme-linked immunosorbent assays, respectively. The protein expression levels of phosphorylation-associated markers were detected using western blot analysis and associated gene expression was determined using RT-qPCR analysis. It was found that GB significantly promoted alkaline phosphatase activity and osteoblastic mineralization in the MC3T3-E1 cells. In addition, the mRNA expression and secretion levels of VEGF in the MC3T3-E1 cells were significantly increased in MC3T3-E1 cells treated with GB. SB203580, a specific
\end{abstract}

Correspondence to: Dr Xuenong Zou, Guangdong Provincial Key Laboratory of Orthopedics and Traumatology, The First Affiliated Hospital of Sun Yat-Sen University, 58 Zhongshan 2nd Road. Guangzhou, Guangdong 510080, P.R. China

E-mail: zxnong@hotmail.com

Dr Chi Zhang, Department of Pharmacology, Peking University International Hospital, No. 1 Life Science Park Road, Changping, Beijing 102206, P.R. China

E-mail: chi.zhang@case.edu

Key words: ginkgolide B, vascular endothelial growth factor, differentiation, MC3T3-E1, mitogen-activated protein kinase inhibitor of p38 mitogen-activated protein (MAP) kinase, markedly suppressed the GB-induced p38 kinase phosphorylation and GB-induced synthesis of VEGF. PD98059, an inhibitor of the upstream kinase, which activates p44/p42 MAP kinase, had minimal effect on the GB-induced phosphorylation of p44/p42 MAP kinase or the GB-induced synthesis of VEGF. Taken together, these results indicated that GB promoted osteoblastic differentiation of the MC3T3-E1 cells through VEGF, and that the p38, but not the p44/p42 MAP kinase signaling pathway, was involved in the GB-induced synthesis of VEGF.

\section{Introduction}

Ginkgo biloba has been used as a medicine in China for $>5,000$ years. Ginkgo biloba extracts, isolated from the leaves of the Ginkgo biloba tree, contain flavonoid and terpenoid substances (1). It has antioxidant effects, acting as a scavenger of free radicals, has a relaxing effect on vascular walls, an antagonistic action on platelet-activating factor, beneficial effects on blood flow and microcirculation, and it stimulates neurotransmitters (2). A number of studies have demonstrated that ginkgolides exhibit protective effects on tissue abnormalities, which include myocardial ischemia reperfusion injury (3), ischemic brain damage (4) neuronal apoptosis (5), hypoxia-induced memory deficits and neuronal DNA damage (6). These effects are considered to be of benefit in the treatment of diseases that are associated with the production of free radicals, including ischemic heart disease, cerebral infarction, chronic inflammation and aging $(7,8)$. The ginkgolides demonstrated to be present in the terpenoid extracts can be divided into isotypes A, B, C, M and $\mathrm{J}$, with ginkgolide $\mathrm{B}\left(\mathrm{GB} ; \mathrm{C}_{20} \mathrm{H}_{24} \mathrm{O}_{10}\right)$ exhibiting the highest biological activity (9).

The GB ginkgolide is a major constituent of the terpenoid fraction. A number of studies have shown that GB possesses neuroprotective effects on various brain injuries, including permanent focal ischemia, transient focal ischemia and ischemia-reperfusion injury (10), by exerting antioxidant effects, reducing brain edema or inhibiting cell apoptosis $(11,12)$.

To the best of our knowledge, the majority of previous studies have focused on the neuroprotective effects of GB. 
Our previous study (13) indicated that GB promotes bone marrow-derived endothelial progenitor cell proliferation, migration and adhesion, and the induction of angiogenesis through vascular endothelial growth factor (VEGF). As the effect of GB on osteoblast-like MC3T3-E1 cells has not been examined previously. The present study aimed to investigate the effect and underlying mechanism of GB on osteogenic differentiation in the MC3T3E-1 cell line. The results of the present study demonstrated that GB promoted osteoblastic differentiation of the MC3T3-E1 cells through the upregulation of VEGF, and that the p38 mitogen-activated protein (MAP) kinase signaling pathway is involved in GB-induced expression of VEGF. These findings suggest GB may be important in the treatment of osteoporosis.

\section{Materials and methods}

Cell culture. Murine osteoblastic MC3T3-E1 cells (American Type Culture Collection, Manassas, VA, USA) were cultured in a $5 \% \mathrm{CO}_{2}$ atmosphere at $37^{\circ} \mathrm{C}$ in $\alpha$-MEM (Hyclone; GE Healthcare Life Sciences, Logan, UT, USA) containing $10 \%$ heat-inactivated fetal bovine serum (FBS; Hyclone; GE Healthcare Life Sciences). On reaching $80 \%$ confluence, the cells were passaged with $0.25 \%$ trypsin (BioSharp, Hefei, China) and transferred to new culture flasks at a ratio of 1:3. To induce osteogenic differentiation, the culture medium was replaced with differentiation medium ( $\alpha$-MEM containing $10 \mathrm{mM} \beta$-glycerophosphate and $50 \mu \mathrm{g} / \mathrm{ml}$ ascorbic acid).

Chemicals. GB (purity $\geq 99 \%$ by HPLC) was obtained from the National Institutes for Food and Drug Control (Beijing, China; http://www.nifdc.org.cn/directory/web/WS02/CL0049/2191. html). The GB was dissolved in dimethylsulfoxide (DMSO; Sigma-Aldrich; Merck Millipore, Darmstadt, Germany) at a concentration of $100 \mathrm{~g} / \mathrm{l}$.

Cell viability assay. The cytotoxic effects of GB on the MC3T3-E1 cells were evaluated using an MTS assay. The MC3T3-E1 cells were seeded in a 96-well plate at 10,000 cells per well and cultured for $24 \mathrm{~h}$ at $37^{\circ} \mathrm{C}$. Following rinsing with phosphate-buffered saline (PBS), the cells were treated with various concentrations of $\mathrm{GB}(0,1.25,5,20$, 80 and $160 \mu \mathrm{g} / \mathrm{l})$ in fresh medium for $48 \mathrm{~h}$. The viable cells were then treated with newly prepared medium containing $20 \mu \mathrm{l}$ of $2 \mathrm{mg} / \mathrm{ml}$ MTS and $100 \mu \mathrm{l}$ of $\alpha$-MEM (10\% FBS) in a $\mathrm{CO}_{2}$ incubator for $3 \mathrm{~h}$. The MTS was transformed by the living cells to a purple formazan dye, which was dissolved in $100 \mu \mathrm{l}$ DMSO by shaking at $150 \mathrm{rpm}$ for $10 \mathrm{~min}$ on an ELISA shaker (Gentaur, Brussels, Belgium). Finally, the relative colorimetric intensity of each well was evaluated using a Varioskan flash multimode reader (Thermo Fisher Scientific Inc., Waltham, MA, USA) at a $490 \mathrm{~nm}$ wavelength.

Measurement of alkaline phosphatase (ALP) activity. The MC3T3-E1 cells were seeded in a 96-well plate at 10,000 cells per well, and placed in a $5 \% \mathrm{CO}_{2}$ incubator at $37^{\circ} \mathrm{C}$ for 7 and 14 days, respectively. Following being rinsed with PBS, the MC3T3-E1 cells were treated with $20 \mu \mathrm{g} / \mathrm{ml}$ GB in fresh medium for 4 days. Following removal of the medium, the cells in each well were incubated with $100 \mu \mathrm{l}$ of
ALP buffer solution for $10 \mathrm{~min}$. The cells of each well were treated with $100 \mu \mathrm{l}$ of $\mathrm{pNPP}$ at $37^{\circ} \mathrm{C}$ for $15 \mathrm{~min}$ to determine the ALP activity. Subsequently, $100 \mu \mathrm{l}$ of $2 \mathrm{M} \mathrm{NaOH}$ was added to terminate the reaction. Finally, the conversion of p-nitrophenyl phosphate to p-nitrophenol was determined using a Varioskan flash multimode reader (Thermo Fisher Scientific Inc.) at a wavelength of $450 \mathrm{~nm}$. The intensity of ALP activity relative to that of the control group in each well was determined.

Alizarin red staining. On days 14 and 21, the cultured cells were fixed for the detection of Alizarin Red staining (Sigma-Aldrich; Merck Millipore). Briefly, the cells were fixed with ice-cold $70 \%$ ethanol for $60 \mathrm{~min}$, washed three times with PBS, and stained with Alizarin Red S $(40 \mathrm{mM}$; $\mathrm{pH}$ 4.2) for $10 \mathrm{~min}$, followed by rinsing with PBS three times. Images of the stained nodules were captured using a digital camera (Nikon C-SHG; Nikon Corporation, Tokyo, Japan). Subsequently, $50 \mu 110 \%$ cetylpyridinium chloride was added to each well, cultured at room temperature for $20 \mathrm{~min}$ and the relative colorimetric intensity of each well was evaluated using a Varioskan Flash Multimode Reader (Thermo Fisher Scientific, Inc.) at a wavelength of $560 \mathrm{~nm}$. Finally, according to the standard curve, the optical density value was converted to concentration.

Reverse-transcription-quantitative polymerase chain reaction (RT-qPCR) analysis. The total RNA of the MC3T3-E1 cells was extracted using TRIzol reagent (Invitrogen; Thermo Fisher Scientific, Inc.). Following subsequent DNase digestion (Invitrogen; Thermo Fisher Scientific, Inc.), $500 \mathrm{ng}$ of RNA was used to synthesize $10 \mu \mathrm{l}$ of cDNA using an PrimeScript ${ }^{\circledR}$ RT Master Mix kit (Takara Biotechnology, Co., Ltd., Dalian, China). The qPCR reactions were performed in a CFX Connect ${ }^{\mathrm{TM}}$ real time system (Bio-Rad Laboratories, Inc., Hercules, CA, USA) using All-in-One ${ }^{\mathrm{TM}}$ qPCR mix (GeneCopoeia, Guangzhou, China). SYBR Green Master mix (GeneCopoeia) was used for all PCR experiments. Thermocycling conditions were as follows: $95^{\circ} \mathrm{C}$ for $20 \mathrm{sec}$ for pre-denaturation; and 40 cycles of $95^{\circ} \mathrm{C}$ for $3 \mathrm{sec}$ and $60^{\circ} \mathrm{C}$ for $30 \mathrm{sec}$. The expression in each sample was evaluated in three technical replicates. The specificity of primer pairs and absence of primer dimers was validated by analysis of the dissociation curves and agarose gel electrophoresis. The comparative $\mathrm{Cq}$ method (14) was used for data analysis. The level of expression in each sample was normalized to the mRNA level of glyceraldehyde 3-phosphate dehydrogenase (GAPDH). The mean expression from three experiments was calculated. The sequences of the primers used in the present study were as follows: VEGF, forward 5'GGACCCTGGCTT TACTGCTGTACC-3' and reverse 5'TCACCGCCTTGG CTTGTCACA-3'; Osx, forward 5'-GCAAGGCTTCGCATC TGAA-3 and reverse 5'-TAGCAGGTTGCTCTGCTC-3'; GAPDH, forward 5'-ACCACAGTCCATGCCATCAC-3' and reverse 5'-TCCACCACCCTGTTGCTGTA-3'.

Western blot analysis. The proteins were isolated from MC3T3-E1 cells using RIPA lysis buffer (Google Biological Technology Co., Ltd., Wuhan, China) and concentration was determined by the BCA Protein assay kit (Beyotime Institute 
of Biotechnology, Haimen, China) according to the manufacturer's protocols. The equal samples of proteins $(30 \mu \mathrm{g})$ were separated on 10\% SDS-PAGE gels and transferred onto a PVDF membrane followed by western blot analysis. Briefly, $5 \%$ milk in TBS containing $0.1 \%$ Tween- 20 was used to block non-specific binding. The membrane was incubated with anti-VEGF rabbit polyclonal antibody (Merck Millipore; cat. no. AB1876), P-38 polyclonal antibody (Cell Signaling Technology, Inc., Danvers, MA, USA; cat. no. 9228), phosphorylated (phospho)-specific P-38 polyclonal antibody (Cell Signaling Technology, Inc.; cat. no. 4092), phospho-specific p44/p42 (Cell Signaling Technology, Inc.; cat. no. 4695), or p44/p42 MAP kinase antibodies (Cell Signaling Technology, Inc.; 9106) overnight at $4^{\circ} \mathrm{C}$ at a dilution of 1:1,000, followed by extensive washing with PBS and incubation for $1 \mathrm{~h}$ at $37^{\circ} \mathrm{C}$ with horseradish peroxidase-conjugated secondary antibody (1:20,000; Cell Signaling Technology, Inc.; cat. no. ). Following antibody incubation and washes with PBS, an ECL kit (GE Healthcare Life Sciences, Chalfont, UK) was used for detection.

Enzyme-linked immunosorbent assay (ELISA). The MC3T3-E1 cells were cultivated and treated with GB, as described for the cell viability assay. Following incubation with GB for 24 and $48 \mathrm{~h}$ respectively, the supernatants were harvested and used for the ELISA assay (eBioscience, Inc., San Diego, CA, USA), according to the manufacturer's protocol.

Statistical analysis. All data are expressed as the mean \pm standard deviation. Statistical analyses were performed using SPSS software (version 13.0; SPSS, Inc., Chicago, IL, USA). All data were analyzed using one-way analysis of variance and Student's $t$ test. $\mathrm{P}<0.05$ was considered to indicate a statistically significant difference. All experiments were performed independently at least three times.

\section{Results}

Effects of GB on the viability of MC3T3E1 cells. To determine the effects of various concentrations of GB on the cell viability of MC3T3E1 cells, which are have the potential to differentiate into osteoblast cells on culture in osteoblastic differentiation medium, an MTS assay was performed. The cells were treated with different concentrations of GB for $48 \mathrm{~h}$ and cell viability was assessed using the MTS assay. As shown in Fig. 1, GB marginally increased the viability of the MC3T3-E1 cells within a $1.25-160 \mu \mathrm{g} / \mathrm{ml}$ dose range, with $20 \mu \mathrm{g} / \mathrm{ml}$ GB showing the maximal effect.

Effects of GB on osteoblastic differentiation in MC3T3-E1 cells. ALP is a well-recognized marker for the differentiation of osteoblasts, and to determine the effects of GB on the activities of ALP in MC3T3 cells, ALP activity assays were performed. The MC3T3-E1 cells were cultured in $\alpha$-MEM (control), GB $(20 \mu \mathrm{g} / \mathrm{ml})$, osteogenic medium and osteogenic medium supplemented with $20 \mu \mathrm{g} / \mathrm{ml}$ GB for 1 and 2 weeks, respectively. The ALP activity in the cells treated with osteogenic medium supplemented with GB was significantly higher, compared with those in the control cells and cells

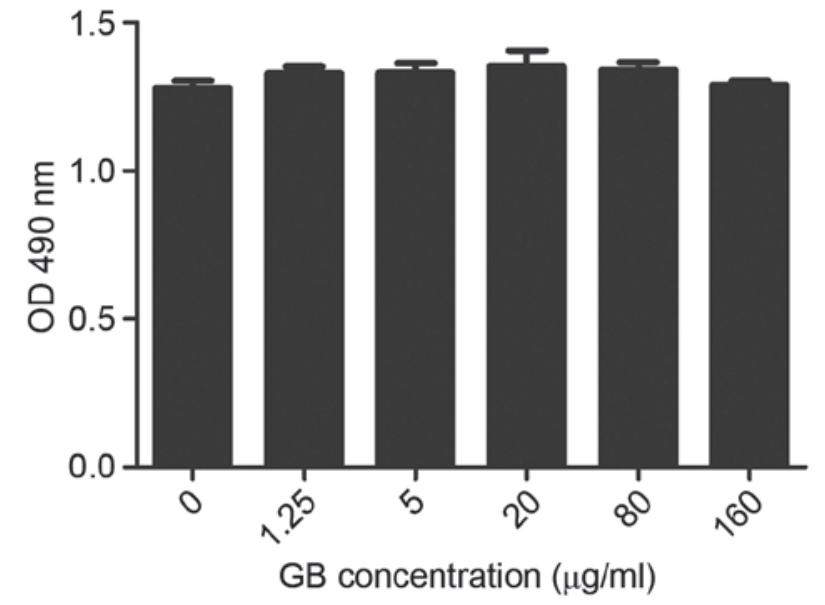

Figure 1. Effect of GB on the viability of MC3T3-E1 cells. The cells were seeded in 96-well plates $\left(1 \times 10^{4}\right.$ cells/well) for $24 \mathrm{~h}$, and then treated with different concentrations of GB for another $48 \mathrm{~h}$. Cellular proliferation was determined using an MTS assay. Each value represents the mean + standard deviation of three repeated experiments. GB, ginkgolide B; OD, optical density.

treated with osteogenic medium alone at 1 and 2 weeks, respectively (Fig. 2A). These results indicated that GB promoted ALP activity in the MC3T3-E1 cells at the early stage.

To determine the effect of GB on calcium deposition in the MC3T3-E1 cells, mineralization was examined using Alizarin Red staining, based on the results of the staining, quantification of the mineralization was performed. The MC3T3-E1 cells were examined following culture for 2 and 3 weeks in osteogenic medium with or without $20 \mu \mathrm{g} / \mathrm{ml}$ GB. GB significantly increased osteoblastic mineralization in the cells following treatment for 2 and 3 weeks, as visualized by the Alizarin Red S staining (Fig. 2B and C). There was an increase in the concentration of mineralized nodules in the group treated with osteogenic medium supplemented with GB, compared with the control group following culture for 2 and 3 weeks, respectively (Fig. 2B and C).

Effect of GB on the secretion of VEGF in MC3T3-E1 cells. To examine the effect of GB on the expression of VEGF in MC3T3-E1 cells, the present study used RT-qPCR analysis and ELISA assays to evaluate the mRNA expression and secretion levels of VEGF in the MC3T3-E1 cells. Over an incubation period of $24 \mathrm{~h}$ with GB, the mRNA expression of VEGF was significantly increased in the MC3T3-E1 cells treated with GB at $20 \mu \mathrm{g} / \mathrm{ml}$, compared with the untreated MC3T3-E1 cells $(\mathrm{P}<0.05$; Fig. 3A). However, the mRNA expression of VEGF decreased following incubation for $48 \mathrm{~h}$ with $20 \mu \mathrm{g} / \mathrm{ml} \mathrm{GB}$ (Fig. 3A). Consistently, the concentration of VEGF in the supernatant was significantly increased in the MC3T3-E1 cells treated with $20 \mu \mathrm{g} / \mathrm{ml} \mathrm{GB}$, compared with the untreated MC3T3-E1 cells at 24 and $48 \mathrm{~h}$, respectively $(\mathrm{P}<0.05$; Fig. 3B).

Effects of SB203580 and PD98059 on the GB-induced synthesis of VEGF in MC3T3-E1 cells. To determine whether p38 MAP kinase or p44/p42 MAP kinase are involved in the GB-induced VEGF synthesis, the present study examined the effects of 
A

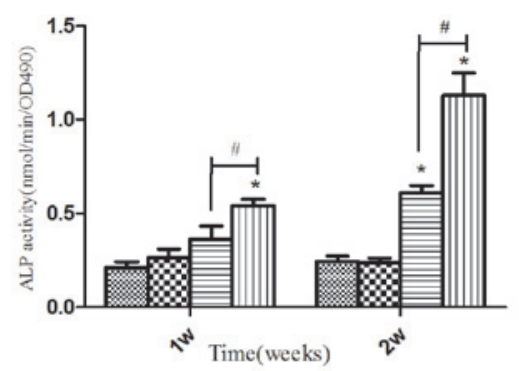

C

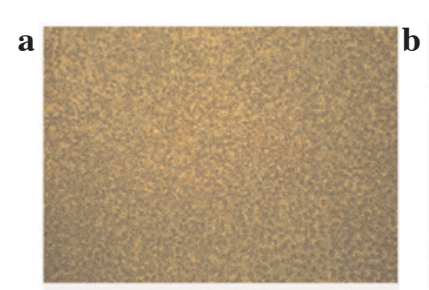

$\mathbf{e}$

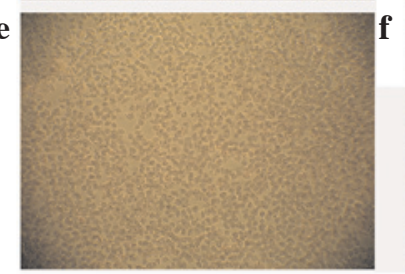

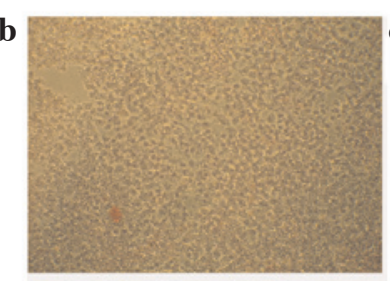

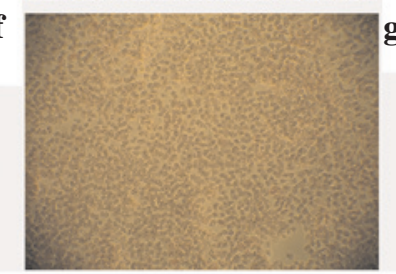

B

网 网 $\mathrm{GB}$

口os 四 OSGB
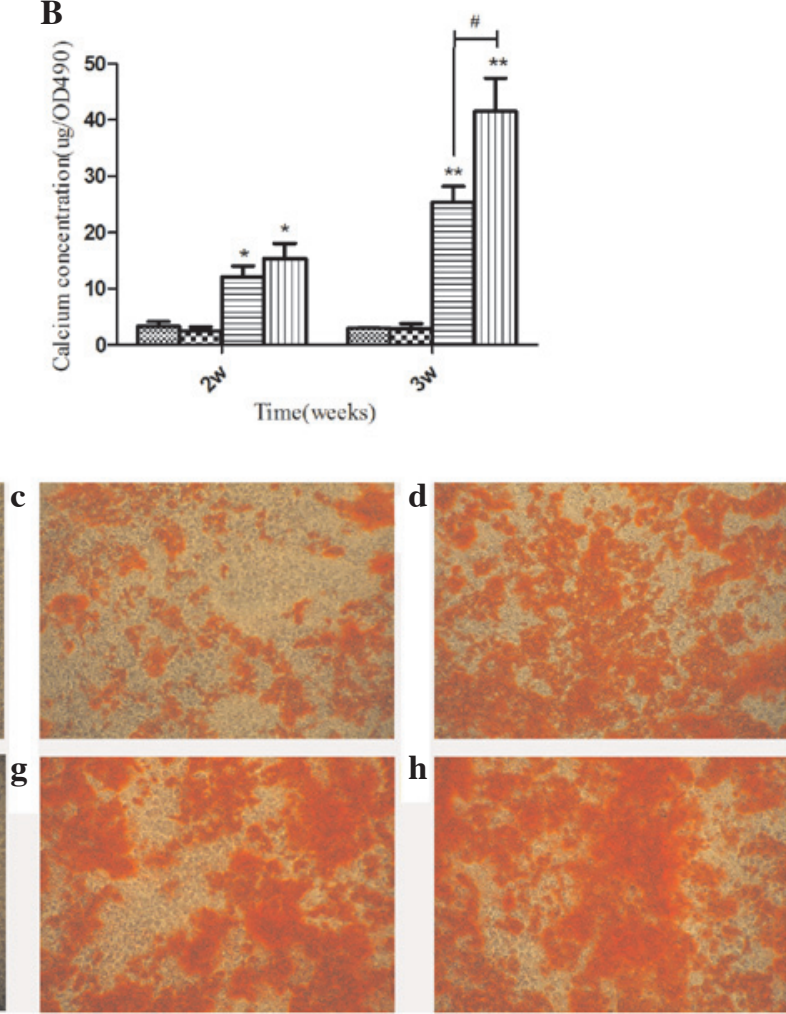

Figure 2. Effect of GB on the osteoblastic differentiation of MC3T3-E1 cells. (A) Measurements of ALP activity in MC3T3-E1 cells. The cells were cultured in $\alpha$-MEM, GB, osteogenic medium and osteogenic medium supplemented with $20 \mu \mathrm{g} / \mathrm{ml} \mathrm{GB}$, respectively. Following treatment of 1 and 2 weeks, the cells were subjected to an ALP activity assay. The data are presented as the mean + standard deviation $\left({ }^{*} \mathrm{P}<0.05\right.$, vs. Con; ${ }^{*} \mathrm{P}<0.05$ vs. OS. $\left.\mathrm{n}=3\right)$. (B) $\mathrm{Quantitative}$ analysis of mineralization, based on the results of the Alizarin Red staining. The data are presented as the mean + standard deviation $\left(\right.$ (" $\mathrm{P}<0.05$ and ${ }^{* *} \mathrm{P}<0.01$, vs. Con; ${ }^{*} \mathrm{P}<0.05$, vs. OS; $\mathrm{n}=3$ ). (C) Images in the top line show Alizarin Red S staining, with calcium deposition stained bright orange/red in the osteocytes at 2 weeks in the (a) Con, (b) GB, (c) OS and (d) OSGB groups. Images below show Alizarin Red S staining with calcium deposition stained bright orange/red in the osteocytes at 3 weeks in the (e) Con, (f) GB, (g) OS and (h) OSGB groups. Magnification, x100. GB, ginkgolide B; OS, osteogenic medium; OSGB, OS supplemented with GB; Con, control; ALP, alkaline phosphatase; OD, optical density.

A

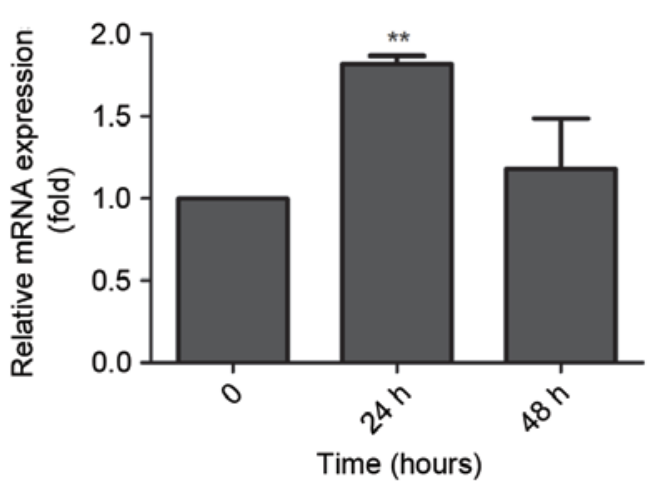

B

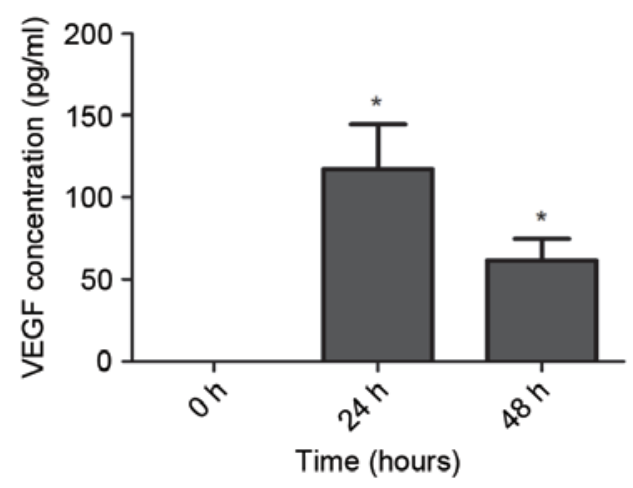

Figure 3. Effect of GB on the expression of VEGF in MC3T3E1 cells. (A) Cells were treated with $20 \mu \mathrm{g} / \mathrm{ml} \mathrm{GB}$ for 24 and $48 \mathrm{~h}$, respectively. The relative mRNA expression levels of VEGF were determined using reverse transcription-quantitative polymerase chain reaction analysis. Results are expressed as the mean + standard deviation ( ${ }^{* *} \mathrm{P}<0.01$, vs. control; $\mathrm{n}=3$ ). (B) Effect of GB on the secretion of VEGF in MC3T3E1 cells. The cells were treated with $20 \mu \mathrm{g} / \mathrm{ml} \mathrm{GB}$ for 24 and $48 \mathrm{~h}$, respectively. The cell supernatants were then collected and used for enzyme-linked immunosorbent assay analysis. Compared with the control group, the secretion of VEGF was increased by the presence of GB at $20 \mu \mathrm{g} / \mathrm{ml}$. Results are expressed as the mean + standard deviation ("P $<0.05$, vs. Control; $\mathrm{n}=3$ ). GB, ginkgolide B; VEGF, vascular endothelial factor.

SB203580, which specifically inhibits p38 MAP kinase, and PD98059, which inhibits the upstream kinase that activating p44/p42 MAP kinase, on the synthesis of VEGF induced by GB. SB203580, which by itself had minimal effect on the synthesis of VEGF, significantly reduced the GB-stimulated mRNA expression (Fig. 4A) and synthesis (Fig. 4B) of VEGF at a concentration of $30 \mu \mathrm{M}$. By contrast, PD98059 had no significant effect on the mRNA expression of VEGF (Fig. 4C) or GB-stimulated secretion of VEGF (Fig. 4D).

Effects of GB on the phosphorylation of p44/p42 MAP kinase and p38 MAP kinase in MC3T3-E1 cells. In order to 
A

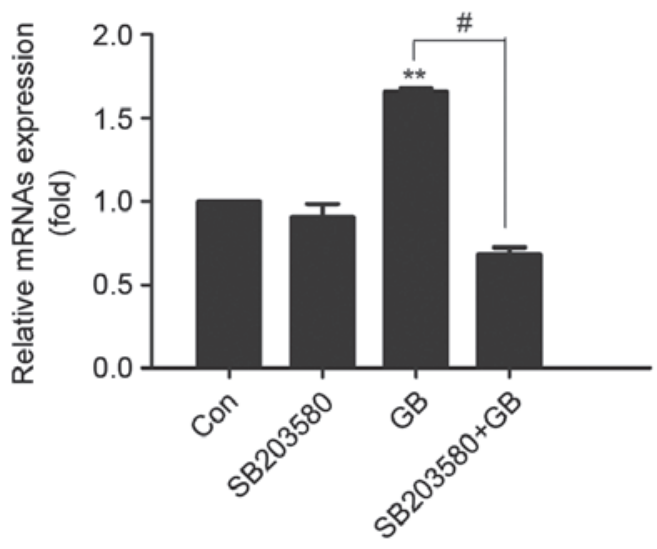

C

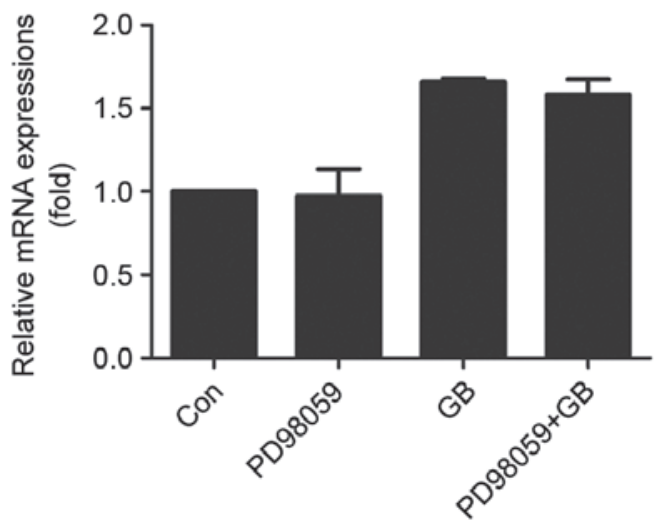

B

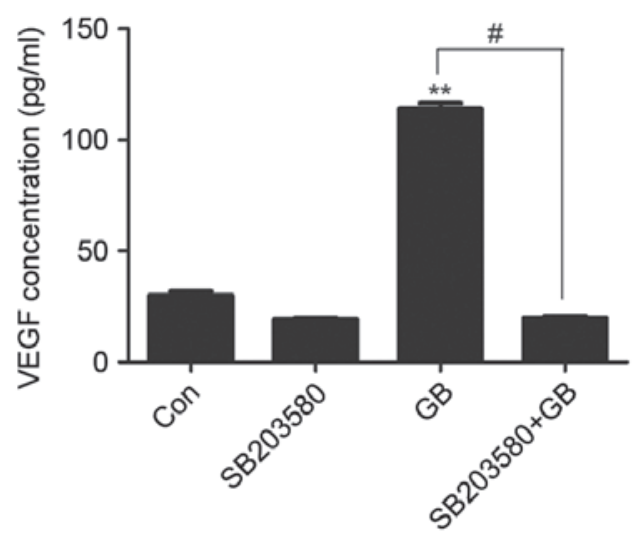

D

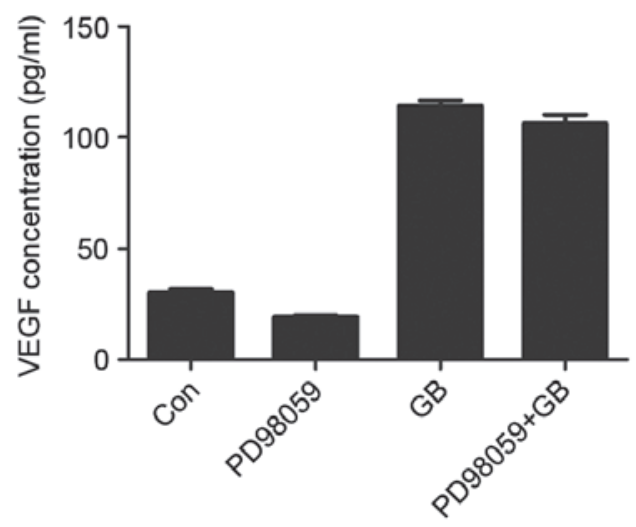

Figure 4. Effect of SB203580 and PD98059 on the expression of VEGF in MC3T3E1 cells. (A) Cells were pretreated with $30 \mu \mathrm{M} \mathrm{SB} 203580$ for $1 \mathrm{~h}$, following which the cells were treated with $20 \mu \mathrm{g} / \mathrm{ml} \mathrm{GB}$ for $24 \mathrm{~h}$. The RNA was extracted and mRNA expression levels of VEGF were determined using RT-qPCR analysis. Results are expressed as the mean + standard deviation $\left({ }^{* *} \mathrm{P}<0.01\right.$, vs. Con; $\left.{ }^{*} \mathrm{P}<0.01 ; \mathrm{n}=3\right)$ (B) Cells were pretreated with $30 \mu \mathrm{M}$ SB203580 for $1 \mathrm{~h}$, followed by treatment with $20 \mu \mathrm{g} / \mathrm{ml} \mathrm{GB}$ for $24 \mathrm{~h}$. Cell supernatants were then collected and used for enzyme-linked immunosorbent assay analysis. The results are expressed as the mean + standard deviation $\left({ }^{* *} \mathrm{P}<0.01\right.$, vs. Con; $\left.{ }^{*} \mathrm{P}<0.01 ; \mathrm{n}=3\right)$. (C) Cells were pretreated with $50 \mu \mathrm{M}$ PD98059 for $1 \mathrm{~h}$, followed by treatment with $20 \mu \mathrm{g} / \mathrm{ml} \mathrm{GB}$ for $24 \mathrm{~h}$. The RNA was extracted and the mRNA expression levels of VEGF were determined using RT-qPCR analysis. The results are expressed as the mean + standard deviation. (D) Cells were pretreated with $50 \mu \mathrm{M}$ PD98059 for $1 \mathrm{~h}$, followed by treatment with $20 \mu \mathrm{g} / \mathrm{ml} \mathrm{GB}$ for $24 \mathrm{~h}$. Cell supernatants were then collected and used for enzyme-linked immunosorbent assay analysis. Results are expressed as the mean + standard deviation. GB, ginkgolide B; VEGF, vascular endothelial growth factor; Con, control; RT-qPCR, reverse transcription-quantitative polymerase chain reaction.

A

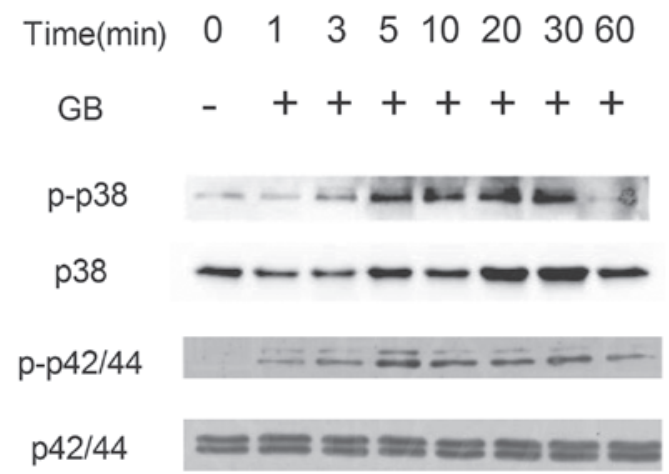

B

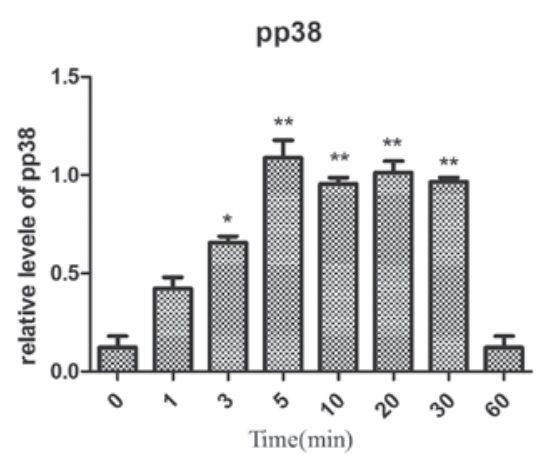

C

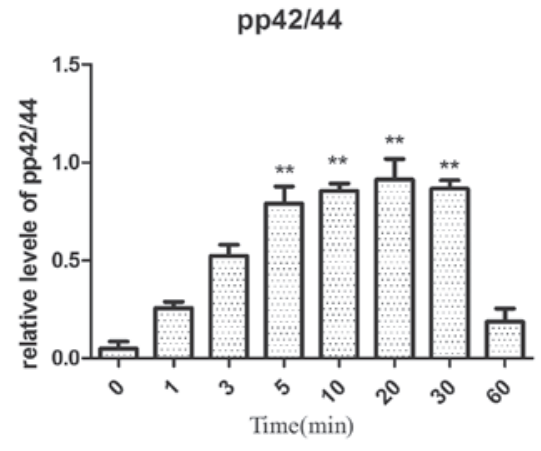

Figure 5. Effects of GB on the phosphorylation of p38 and p42/44 MAP kinase in MC3T3-E1 cells. The cultured cells were stimulated with $20 \mu \mathrm{g} / \mathrm{ml}$ GB for 1, 3, 5, 10, 20,30 and 60 min, respectively. (A) The extracts of cells were subjected to SDS-PAGE and subsequent western blot analysis with antibodies against p-p38 or p42/44 MAP kinase and p38 or p42/44MAP kinase. (B and C) Quantification of the levels of p-p38 and p42/44 be densitometry. "P<0.05, ${ }^{* *} \mathrm{P}<0.01$ vs. 0 min GB, ginkgolide B; MAP, mitogen-activated protein; $\mathrm{p}$-, phosphorylated.

determine whether GB activates p44/p42 MAP kinase and/or p38 MAP kinase, the present study investigated the effects of GB on these MAP kinases and, specifically, their levels of phosphorylation. Treatment with GB led to an increase in the phosphorylation of p44/p42 MAP kinase and p38 MAP kinase in a time-dependent manner (Fig. 5). The significant 
A

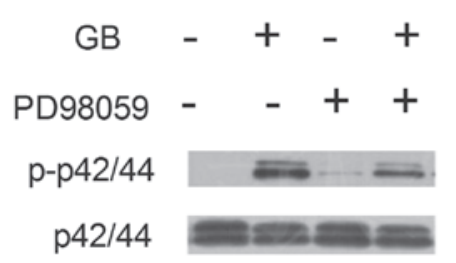

pp42/44

C

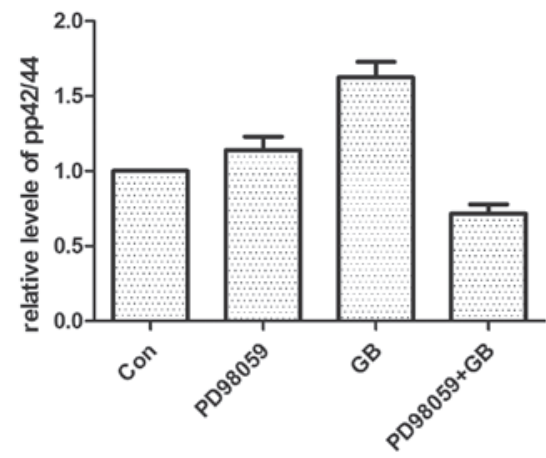

B

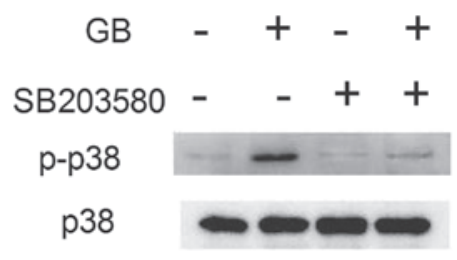

pp38

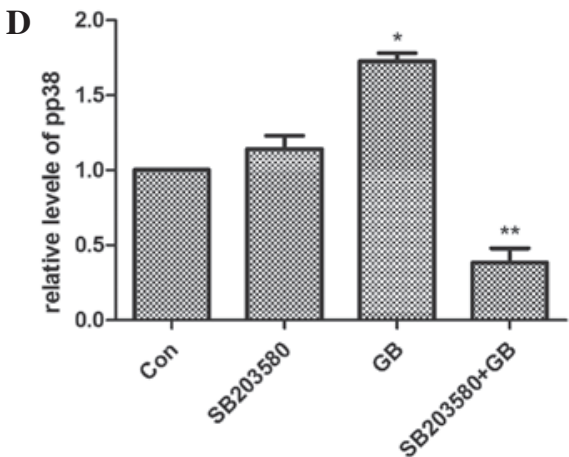

Figure 6. Effects of SB203580 and PD98059 on the GB-induced phosphorylation of p38 MAP kinase and p44/p42 MAP kinase. (A) Effect of PD98059 on GB-1-induced phosphorylation of p42/44 MAP kinase in MC3T3-E1 cells. The cultured cells were pretreated with $50 \mu \mathrm{M}$ of PD98059 for 60 min, and then stimulated with $20 \mu \mathrm{g} / \mathrm{ml} \mathrm{GB}$ for $5 \mathrm{~min}$. Extracts of cells were subjected to SDS-PAGE and incubated with p-p42/44 MAP kinase antibodies or p42/44 MAP kinase antibodies. Similar results were obtained with two additional and different cell preparations. (B) Effect of SB203580 on the GB-1-induced phosphorylation of p38 MAP kinase in MC3T3-E1 cells. The cultured cells were pretreated with $30 \mu \mathrm{M}$ of SB203580 for $60 \mathrm{~min}$, and then stimulated with $20 \mu \mathrm{g} / \mathrm{ml}$ GB for 5 min. Extracts of the cells were subjected to SDS-PAGE and incubated with p-p38 MAP kinase antibodies or p38MAP kinase antibodies. Similar results were obtained with two additional and different cell preparations. (C and D) Quantification of the levels of p-p42/44 and p-p38 by densitometry analysis. * $<0.05$, ${ }^{* * *} \mathrm{P}<0.01$ vs. the Con group. GB, ginkgolide B; MAP, mitogen-activated protein; p-, phosphorylated; Con, control.

stimulatory effects of GB on the phosphorylation of p44/p42 MAP kinase and p38 MAP kinase were observed 5 min post-stimulation (Fig. 5).

Effects of SB203580 and PD98059 on the GB-induced phosphorylation of p38 MAP kinase and p44/p42 MAP kinase in MC3T3-E1 cells. To investigate whether p38 or p44/p42 MAP kinase is involved in the phosphorylation induced by GB in the MC3T3-E1 cells, The MC3T3-E1 cells were pretreated with $30 \mu \mathrm{M}$ SB203580 or $50 \mu \mathrm{M}$ PD98059 prior to treatment with $20 \mu \mathrm{g} / \mathrm{ml} \mathrm{GB}$. As shown in Fig. 6, PD98059 had minimal effect on the GB-induced phosphorylation of p44/p42 MAP kinase (Fig. 6A). SB203580 alone had minimal effect on the phosphorylation of p38 MAP kinase; however, it significantly decreased the GB-induced phosphorylation of p38 MAP kinase (Fig. 6B).

\section{Discussion}

Traditional Chinese medicines have long been used among the Chinese population for the treatment of several diseases and conditions. Several in vitro and in vivo studies have demonstrated that Chinese herbs have positive effects on bone formation, which occur by promoting osteoblastic proliferation and inhibiting osteoclastic formation (15). Li et al (16) found that Naringin, a Chinese herbal medicine, promotes the proliferation and differentiation of bone marrow mesenchymal stem cells and effectively reverses ovariectomy-induced osteoporosis in rats. In a study by Huh et al (17), it was found that Puerariae radix is vital in osteoblastic bone formation and that this may be associated with the angiogenic property of the herb via the increased mRNA expression of VEGF.

GB, a herbal extract from the leaves of the Ginkgo biloba tree, has been shown to inhibit platelet-activating factor (18). Its suggested biological effects include the scavenging of free radicals, reducing oxidative stress, neural damage and platelet aggregation, and possessing anti-inflammatory, antitumor and anti-aging activities (19). Our previous study demonstrated that GB increases the number and functional activities of EPCs, with involvement of Akt/endothelial nitric oxide synthase and MAPK/p38 signaling pathways. However, to the best of our knowledge, whether GB induces osteogenic activity in mouse osteoblast-like MC3T3-E1 cells has not been reported. In the present study, it was found that GB promoted osteoblastic differentiation of MC3T3-E1 cells through the upregulation of VEGF, and the p38 MAP kinase signaling pathways was involved in the GB-induced synthesis of VEGF.

A number of previous reports have demonstrated a close association between angiogenesis, fracture healing and bone growth. It is known that, during bone formation, angiogenesis and osteogenesis are coupled spatially and temporally (20). The critical step in endochondral ossification is the introduction of highly vascularized bone to replace the avascular cartilage. The mechanism underlying angiogenesis involves in the action of VEGF, which is a potent angiogenic peptide and has mitogenic and chemotactic effects on endothelial cells $(21,22)$.

There are an increasing number of reports indicating that VEGF has a positive effect in regulating osteoblast activity. D'Alimonte et al (23) demonstrated that VEGF enhances 
the proliferation and osteogenic differentiation of human dental pulp stem cells in vitro. Hah et al (24) demonstrated that VEGF stimulates the differentiation of cultured human periosteal-derived cells into the osteoblastic and that VEGF may act as an autocrine growth factor for the osteoblastic differentiation of cultured human periosteal-derived cells Tan et al (25) reported that VEGF promotes bone remodeling by direct effects on osteoblasts via regulating the gene expression of ALP, osteocalcin and osteoprotegerin through the VEGF receptor 2 signaling pathway. In the processes of bone formation and fracture healing, a study by Deckers et al (26) demonstrated that the VEGF produced by osteoblast-like cells enhances osteoblastic differentiation by stimulating endothelial cells to secrete growth factors and cytokines, which induce mesenchymal cells into osteogenic differentiation. In the present study, it was found that GB significantly increased ALP activity and osteoblastic mineralization in MC3T3-E1 cells. In addition, GB significantly increased the mRNA expression and secretion levels of VEGF in the MC3T3-E1 cells. These findings suggested that GB promoted the osteogenic differentiation of MC3T3-E1 cells through the upregulation of VEGF.

A previous study demonstrated that p38 MAP kinase, but not p42/p44 MAP kinase, is involved in prostaglandin E1-induced VEGF synthesis in MC3T3-E1 cells (27). Kozawa et al (28) showed that endothelin-1 stimulates VEGF synthesis via endothelin A receptor in osteoblasts, and that p38 MAP kinase is involved in endothelin-1-induced VEGF synthesis. Tokuda et al (29) reported that p44/p42 MAP kinase and p38 MAP kinase are involved in transforming growth factor- $\beta$-stimulated VEGF synthesis in osteoblasts. In the present study, in order to detect the role of $\mathrm{p} 44 / \mathrm{p} 42$ and p38 MAP kinase in the GB-induced the expression of VEGF in MC3T3-E1 cells, the effects of GB on the phosphorylation of these MAP kinases were examined. It was found that GB induced the phosphorylation of p44/p42 and p38 MAP kinase in a time-dependent manner. Furthermore, SB203580, a specific inhibitor of p38 MAP kinase, markedly suppressed the GB-induced p38 kinase phosphorylation and GB-stimulated VEGF synthesis. PD98059, an inhibitor of the upstream kinase, which activates p44/p42 MAP kinase, had minimal effect on the GB-induced phosphorylation of p44/p42 MAP kinase or GB-induced VEGF synthesis. These data indicated that the $\mathrm{p} 38$, but not the $\mathrm{p} 44 / \mathrm{p} 42$, MAP kinase signaling pathway is involved in the GB-induced expression of VEGF.

A series of studies have examined the role of MAP kinases in modulating osteogenic differentiation. Greenblatt et al demonstrated that p38 promoted skeleton formation and bone homeostasis through runt-related transcription factor 2, which is a key transcription factor associated with osteoblast differentiation $(30,31)$. A study by $\mathrm{Hu}$ et al confirmed that p38 has a positive effect in the early and late osteogenesis of osteoblasts, bone marrow osteoprogenitor cells and the MC3T3-E1 osteoblast line $(32,33)$.

In conclusion, the results obtained in the present study demonstrated that GB enhanced the osteoblastic differentiation of MC3T3-E1 cells through VEGF, and that the p38 MAP kinase signaling pathway was involved in the GB-induced expression of VEGF. These findings suggest that
GB is a potential candidate target for treating or preventing osteoporosis.

\section{Acknowledgements}

The present study was supported by the Key Program of National Natural Science of Foundation of China (grant no. 31430030), and the National Program on Key Basic Research Project (973 Program; grant no. 2012CB619105).

\section{References}

1. Liang L: The history of cultivation techniques of Ginkgo biloba in China. Agricultural Archaeology 1: 259-261, 2002.

2. Dias MA, Sampaio AL, Venosa AR, Meneses EA and Oliveira CA: The chemopreventive effect of Ginkgo biloba extract 761 against cisplatin ototoxicity: A pilot study. Int Tinnitus J 19: $12-19,2015$.

3. Shen J, Wang J, Zhao B, Hou J, Gao T and Xin W: Effects of EGb 761 on nitric oxide and oxygen free radicals, myocardial damage and arrhythmia in ischemia-reperfusion injury in vivo. Biochim Biophys Acta 1406: 228-236, 1998.

4. Zhang WR, Hayashi T, Kitagawa H, Sasaki C, Sakai K, Warita H, Wang JM, Shiro Y, Uchida M and Abe K: Protective effect of ginkgo extract on rat brain with transient middle cerebral artery occlusion. Neurol Res 22: 517-521, 2000.

5. Ahlemeyer B, Mowes A and Krieglstein J: Inhibition of serum deprivation- and staurosporine-induced neuronal apoptosis by Ginkgo biloba extract and some of its constituents. Eur J Pharmacol 367: 423-430, 1999.

6. Abdel-Wahab BA and Abd El-Aziz SM: Ginkgo biloba protects against intermittent hypoxia-induced memory deficits and hippocampal DNA damage in rats. Phytomedicine 19: 444-450, 2012.

7. Nash KM and Shah ZA: Current perspectives on the beneficial role of Ginkgo biloba in neurological and cerebrovascular disorders. Integr Med Insights 10: 1-9. 2015.

8. Nabavi SM, Habtemariam S, Daglia M, Braidy N, Loizzo MR, Tundis R and Navabi SF: Neuroprotective effects of Ginkgolide B against ischemic stroke: A review of current literature. Curr Top Med Chem 15: 2222-2232, 2015.

9. Li R, Chen B, Wu W, Bao L, Li J and Qi R: Ginkgolide B suppresses intercellular adhesion molecule-1 expression via blocking nuclear factor-kappaB activation in human vascular endothelial cells stimulated by oxidized low-density lipoprotein. J Pharmacol Sci 110: 362-369, 2009.

10. Huang M, Qian Y, Guan T, Huang L, Tang X and Li Y: Different neuroprotective responses of Ginkgolide B and bilobalide, The Two Ginkgo Components Hyperglycemia. Eur J Pharmacol 677: 71-76, 2012.

11. Huang JY SJMS: Protective effects of ginkgolide B on cerebral ischemia reperfusion injury in rats. Chin Pharmacol Bull: 269-272, 2008.

12. Botao Y, Ma J, Xiao W, Xiang Q, Fan K, Hou J, Wu J and Jing W: Protective effect of ginkgolide B on high altitude cerebral edema of rats. High Alt Med Biol 14: 61-64, 2013.

13. Tang Y, Huang B, Sun L, Peng X, Chen X and Zou X: Ginkgolide B promotes proliferation and functional activities of bone marrow-derived endothelial progenitor cells: Involvement of Akt/eNOS and MAPK/p38 signaling pathways. Eur Cell Mater 21: 459-469, 2011.

14. Livak KJ and Schmittgen TD: Analysis of relative gene expression data using real-time quantitative PCR and the 2(-Delta Delta C(T)) Method. Methods 25: 402-408, 2001.

15. Yang Y, Chin A, Zhang L, Lu J and Wong RW: The role of traditional Chinese medicines in osteogenesis and angiogenesis. Phytother Res 28: 1-8, 2014

16. Li N, Jiang Y, Wooley PH, Xu Z and Yang SY: Naringin promotes osteoblast differentiation and effectively reverses ovariectomy-associated osteoporosis. J Orthop Sci 18: 478-485, 2013.

17. Huh JE, Yang HR, Park DS, Choi DY, Baek YH, Cho EM, Cho YJ, Kang-Il K, Kim DY and Lee JD: Puerariae radix promotes differentiation and mineralization in human osteoblast-like SaOS-2 cells. J Ethnopharmacol 104: 345-350, 2006. 
18. Lamant V, Mauco G, Braquet P, Chap H and Douste-Blazy L: Inhibition of the metabolism of platelet activating factor (PAF-acether) by three specific antagonists from Ginkgo biloba. Biochem Pharmacol 36: 2749-2752, 1987.

19. Chan PC, Xia Q and Fu PP: Ginkgo biloba leave extract: Biological, medicinal and toxicological effects. J Environ Sci Health C Environ Carcinog Ecotoxicol Rev 25: 211-244, 2007.

20. Xie H, Cui Z, Wang L, Xia Z, Hu Y, Xian L, Li C, Xie L, Crane J, Wan M, et al: PDGF-BB secreted by preosteoclasts induces angiogenesis during coupling with osteogenesis. Nat Med 20: 1270-1278, 2014.

21. Street J, Winter D, Wang JH, Wakai A, McGuinness A and Redmond HP: Is human fracture hematoma inherently angiogenic? Clin Orthop Relat Res: 224-237, 2000

22. Geiger F, Bertram H, Berger I, Lorenz H, Wall O, Eckhardt C, Simank HG and Richter W: Vascular endothelial growth factor gene-activated matrix (VEGF165-GAM) enhances osteogenesis and angiogenesis in large segmental bone defects. J Bone Miner Res 20: 2028-2035. 2005.

23. D'Alimonte I, Nargi E, Mastrangelo F, Falco G, Lanuti P, Marchisio M, Miscia S, Robuffo I, Capogreco M, Buccella S, et al: Vascular endothelial growth factor enhances in vitro proliferation and osteogenic differentiation of human dental pulp stem cells. J Biol Regul Homeost Agents 25: 57-69, 2011.

24. Hah YS, Jun JS, Lee SG, Park BW, Kim DR, Kim UK, Kim JR and Byun JH: Vascular endothelial growth factor stimulates osteoblastic differentiation of cultured human periosteal-derived cells expressing vascular endothelial growth factor receptors. Mol Biol Rep 38: 1443-1450, 2011.

25. Tan YY, Yang YQ, Chai L, Wong RW and Rabie AB: Effects of vascular endothelial growth factor (VEGF) on MC3T3-E1. Orthod Craniofac Res 13: 223-228, 2010.
26. Deckers MM, Karperien M, van der Bent C, Yamashita T, Papapoulos SE and Löwik CW: Expression of vascular endothelial growth factors and their receptors during osteoblast differentiation. Endocrinology 141: 1667-1674, 2000.

27. Tokuda H, Kozawa O, Miwa $M$ and Uematsu T: p38 mitogen-activated protein (MAP) kinase but not p44 p42 MAP kinase is involved in prostaglandin E1-induced vascular endothelial growth factor synthesis in osteoblasts. J Endocrinol 170: 629-638, 2001.

28. Kozawa O, Kawamura H, Hatakeyama D, Matsuno H and Uematsu T: Endothelin-1 induces vascular endothelial growth factor synthesis in osteoblasts involvement of p38 mitogen-activated protein kinase. Cellular Signal 12: 375-380, 2000.

29. Tokuda H, Hatakeyama D, Akamatsu S, Tanabe K, Yoshida M, Shibata $\mathrm{T}$ and Kozawa O: Involvement of MAP kinases in TGF-beta-stimulated vascular endothelial growth factor synthesis in osteoblasts. Arch Biochem Biophys 415: 117-125, 2003.

30. Chen M, Chen PM, Dong QR, Huang Q, She C and Xu W: p38 signaling in titanium particle-induced MMP-2 secretion and activation in differentiating MC3T3-E1 cells. J Biomed Mater Res A 102: 2824-2832, 2014.

31. Greenblatt MB, Shim JH, Zou W, Sitara D, Schweitzer M, Hu D, Lotinun S, Sano Y, Baron R, Park JM, et al: The p38 MAPK pathway is essential for skeletogenesis and bone homeostasis in mice. J Clin Invest 120: 2457-2473, 2010.

32. Hu Y, Chan E, Wang SX and Li B: Activation of p38 mitogen-activated protein kinase is required for osteoblast differentiation. Endocrinology 144: 2068-2074, 2003.

33. Thouverey $\mathrm{C}$ and Caverzasio J: The $\mathrm{p} 38 \alpha$ MAPK positively regulates osteoblast function and postnatal bone acquisition. Cell Mol Life Sci 69: 3115-3125, 2012. 